\title{
THE WAYS OF RESEARCHING ESP LEARNERS' NEEDS AS SEEN BY TEACHERS OF UKRAINIAN UNIVERSITIES
}

\author{
Iryna Soroka \\ "Law Institute for "KNEU named after Vadym Hetman”, Kyiv, Ukraine \\ ira.sor@ukr.net
}

\begin{abstract}
The aim of this article is to introduce different ways of researching learners' needs and discuss the results of the research, conducted among Ukrainian ESP university teachers, to emphasise the need for universities to develop and implement a Continuing Professional Development policy for teachers of English. The qualitative method (questionnaire) was used to interview sixty teachers of ESP from Ukrainian universities to identify their awareness of the importance of learners' needs analysis and various ways of its research. The results of this research show that the majority of teachers from Ukrainian universities are aware of the importance of learners' needs analysis in an ESP class. Ukrainian teachers consider introspection, workplace tours, the Internet, textbooks and training courses to be the most meaningful learners' needs. However, all surveyed teachers get information about their students' needs by interviewing them. There is a huge reliance on teachers' experience. The results of the survey have also shown that the majority of respondents discuss with subject teachers and students the topics, terminology, materials for ESP curriculum. This research has lead to the conclusion that the usage of different ways and multiple sources will increase the quality of gathered information about learners' needs.
\end{abstract}

Keywords: ESP; absolute and variable characteristics; learners' needs; Continuing Professional Development.

\section{Introduction}

Influenced by globalisation, ESP has become a key player in English language teaching. But it has only recently gained its importance in Ukraine as students are prepared for their future work in different spheres: law, engineering, medicine, technology, chemistry, physics, economy, management, logistics, finance, biology etc. Nowadays more and more Ukrainian universities introduce double diploma courses. Due to different programmes, there are more opportunities for Ukrainian students to study abroad. Ukraine is determined to join the EU hence there will be more possibilities to work in international companies, where the high level (B2 - Upper Intermediate) of the English language proficiency is the must. Therefore, students' needs are the core for ESP course desighn. Many educators around the world consider learners' needs analysis to be a valuable tool and think that it can be used to link the students' present academic learning with their future professional needs.

\section{Literature review}

Different definitions of the term ESP exist in the scientific literature. Hutchinson and Waters (1987) introduced the following definition: "ESP must be seen as an approach not as a product. ESP is not a particular kind of language or methodology, nor does it consist of a particular type of teaching material. Understood properly, it is an approach to language learning, which is based on learner need" (p.19).

Dudley-Evans and St. John (as cited in Bojović, 2006) identified absolute and variable characteristics of ESP (p.488). Absolute characteristics are:

1. ESP is designed to meet specific needs of the learner;

2. ESP makes use of underlying methodology and activities of the disciplines it serves;

3. ESP is centred on the language (grammar, lexis, register), skills, discourse and genres appropriate to these activities.

Variable characteristics include:

- ESP may be related to or designed for specific disciplines;

- ESP may use, in specific teaching situations, a different methodology from that of general English;

- ESP is likely to be designed for adult learners, either at a tertiary level institution or in a professional work situation;

- ESP is generally designed for intermediate or advanced students. Most ESP courses assume some basic knowledge of the language.

It is widely known that people are motivated by their needs in a hierarchy from basic to the highest level called self-actualisation. Needs analysis (also known as needs assessment), carried out to establish the "what" and the "how" of a course, is the first stage in ESP course development, followed by curriculum design, materials selection, methodology, assessment, and evaluation (Flowerdew, 2013, p.331). This term refers to the techniques for collecting and assessing information relevant to course design. "Needs is actually 
an umbrella term that embraces many aspects, incorporating learners' goals and backgrounds, their language proficiencies, their reasons for taking the course, their teaching and learning preferences, and the situations they will need to communicate in" (Hyland, 2006, p.73).

However, "what distinguishes ESP from General English is not the existence of a need as such but an awareness of the need" (Hutchinson \& Waters, 1987, p.53). These authors consider target needs in terms of necessities (the type of need determined by the demands of the target situation), lacks (learning gap), and wants (students' view on what their needs are).

Having studied the ideas of the British Council course CiVELT (Certificate in Vocational English Language Teaching) (British Council, 2013), and conducted a couple of trainings for university teachers on the topic of needs analysis, the author of this article can introduce three main types of learners' needs: personal, learning and professional (Table 1.).

Types of learners' needs

Table 1

\begin{tabular}{|l|l|l|}
\hline Personal needs & Learning needs & Professional needs \\
\hline age; & learning styles; & job; \\
personality; & previous learning experience; & professional profile; \\
cultural background. & knowledge gaps. & specialised training. \\
\hline
\end{tabular}

Needs analysis is constantly evolving and redefining itself. Before the 1970s, needs analyses were based on teacher intuitions and sometimes informal analyses of students' needs, as noted by West (1994). Nowadays various ways of collecting and analysing needs exist (from simple questionnaires to training courses) and are introduced by scientists.

The framework which outlines the kind of information that the course designer needs to gather from analysis of target needs was described by Hutchinson \& Waters (1987, p. 59; pp.62-63), Songhori (2008, p.8), Boroujeni and Fard (2013, p.37-41), Chovancova (2014, p.46-55). Shortly it includes the following points:

Why is the language needed?

How will the language be used (medium: speaking, writing etc.; types of text: technical manuals, lectures, catalogues etc.)?

What will the content areas be (subject: medicine, engineering etc.)?

Who will the learner use the language with (native speakers or non-native; colleagues, customers)?

Where will the language be used (setting: office, workshop; linguistic context: in own country, abroad etc.)?

Why are the learners taking the course?

What is their learning background?

What resources are available (materials, aids, opportunities for out-of-class activities)?

Who are the learners (age, nationality, socio-cultural background, learning styles etc.)?

When and where will the ESP course take place?

These and other issues (depending on the particular situation) should be considered before the designing and beginning the ESP course. As Lavrysh (2016) states, "universities should provide the education that can match the needs of students and employers. Modern employers' expectations of graduates who ought to be motivated, determined and efficient, impact the direction of the education process" (p.60).

There is no information in our scientific literature about the attitude of Ukrainian ESP university teachers to needs analysis, their awareness of the variety of forms and its usage in ELT (English language teaching), which generated our research.

The objectives of this article are to introduce different aspects of classifying learners' needs and various ways of their research; to present and discuss the results of the research, conducted among Ukrainian ESP university teachers, as for the issue of learners' needs analysis; to emphasise the need for universities to develop and implement a Continuing Professional Development policy for teachers of English with a requirement for regular updates in teaching methodology.

\section{Methods}

In this study, the qualitative method was used. To identify the ESP teachers' awareness of learners' needs analysis importance and its various ways the questionnaire, designed by the author of the article, was used because it seemed to be the most appropriate tool for gathering the views of ESP teachers from Ukrainian universities. It consists of six multiple choice questions. 


\section{Participants}

The participants of this research are a total of 60 ESP teachers (male and female) aged 23-55 from Ukrainian universities (the National Technical University of Ukraine "Igor Sikorsky Kyiv Polytechnic University"; Kyiv National Economic University named after Vadym Hetman; "KROK" University; National Aviation University). They are teachers, senior lecturers and assistant professors.

\section{Instruments}

The participants of the research were asked to answer six questions of the questionnaire:

1. Are your students' needs in ESP:

a) important for you; b) somewhat important; c) not important.

2. How do you get information about your students' needs:

a) interviewing them; b) using special questionnaires (needs analysis forms); c) other (specify).

3. Do you ever consult with subject teachers as for the topics, terminology, materials for teaching your specialism:

a) often; b) from time to time; c) never.

4. Do you ever consult with your students which topics, terms etc. to study:

a) often; b) from time to time; c) never.

5. How do you feel if you don't know, can't explain the notions or terms from the specialism you teach (English for Law, Economics etc.)? Write your comment.

The sixth point contained a table with ten of possible ways to research learners' needs. The task was to choose those of them the interviewees find the most useful in their teaching or to suggest their own ways (the table with the results will be introduced later).

\section{Procedure}

Stage one. At this stage, the questionnaire was created in order to identify the ESP teachers' awareness of learners' needs analysis importance and various ways of its implementation.

Stage two. This stage of the study involved the circulation and collection of the survey questionnaires. This occurred at the beginning of the semester.

Stage three. This stage involved calculating and analysing data.

\section{Results}

The results of the study show that:

- for $63 \%$ of ESP university teachers students' needs are important;

- for $37 \%$ they are somewhat important;

- $100 \%$ of surveyed teachers get information about their students' needs by interviewing them;

- $74 \%$ of respondents from time to time consult with subject teachers;

- $13 \%$ often consult and the same number $-13 \%$ never consult with subject teachers as for the topics, terminology, materials for teaching their specialism;

- the same proportion was received as the answer for the fourth question concerning students: $74 \%$ of respondents from time to time consult with students about topics, terms etc. to study;

- $13 \%$ often and $13 \%$ never do that.

As for the fifth question about the feelings of the ESP teachers if they are not able to explain the notions or terms from the specialty they teach, the following comments were collected: "feel uncomfortable", "give this point as home task for students", "feel embarrassed and try to find explanation online", "ask a subject teacher to help or google this point", "feel upset", "feel frustrated", "pretend that I know the answer, but redirect the question to students". Only a small number of responses were less disappointing: "promise to find out. I think it's good to show vulnerability, so students can feel comfortable with their own weaknesses and fears" and "feel OK. I mean, I am not a specialist in law, economics etc.", "say that I am a philologist, not a lawyer", "suggest searching for the answer together", "ask my students to use the Internet, find the answer and present it to the whole class".

The task for the sixth question was to look through the list of the ways of researching learners' needs and decide how useful they might be for university teachers who teach ESP. It contained various ideas from introspection and textbooks to workplace tours and professional qualifications for the given field. The results for this point are introduced in the table below (Table 2.). 
The results of the sixth question (in percentage of respondents)

\begin{tabular}{|l|c|c|c|}
\hline Ways of researching learners' needs & Very useful & $\begin{array}{l}\text { Quite } \\
\text { useful }\end{array}$ & $\begin{array}{l}\text { Waste of } \\
\text { time }\end{array}$ \\
\hline $\begin{array}{l}\text { Introspection (i.e. thinking to yourself about their } \\
\text { field, based on your knowledge and experiences) }\end{array}$ & $25 \%$ & $75 \%$ & - \\
\hline $\begin{array}{l}\text { Asking an expert (e.g. a university professor, an } \\
\text { experienced teacher) }\end{array}$ & $63 \%$ & $25 \%$ & $12 \%$ \\
\hline $\begin{array}{l}\text { Workplace tours (i.e. someone shows you around } \\
\text { their workplace and explains what is happening) }\end{array}$ & $50 \%$ & $50 \%$ & - \\
\hline The Internet & $88 \%$ & $12 \%$ & - \\
\hline Textbooks (aimed at university students) & $88 \%$ & $12 \%$ & - \\
\hline $\begin{array}{l}\text { Training courses and professional qualifications for } \\
\text { the given field }\end{array}$ & $88 \%$ & $12 \%$ & - \\
\hline $\begin{array}{l}\text { Support groups (e.g. online communities of } \\
\text { English teachers in a similar situation to yours) }\end{array}$ & $12 \%$ & $76 \%$ & $12 \%$ \\
\hline Watching professionals in action & $10 \%$ & $42 \%$ & $48 \%$ \\
\hline TV programs and online films (e.g. YouTube) & $70 \%$ & $15 \%$ & $15 \%$ \\
\hline Magazines & $50 \%$ & $40 \%$ & $10 \%$ \\
\hline Other ways (specify) & - & - & - \\
\hline
\end{tabular}

\section{Discussion}

Interpreting the response patterns of the questionnaire in this research, we have come to the conclusion that the majority of teachers from Ukrainian universities are aware of the importance of learners' needs analysis in an ESP class. But still, the alarming thing is that more than the third of the surveyed consider learners' needs analysis in an ESP class only somewhat important. The results of the second point of the questionnaire show that the teachers neither know nor use any other forms of getting information about their students' needs except by interviewing them.

The positive aspect is that almost 90 per cent of the respondents consult with subject teachers as for the topics, terminology, materials for teaching their specialism and with students about topics and terms to study. The responses for the fifth question as for the feelings of university teachers coincide with the results of our previous research (Soroka, 2017, p.176). The teachers feel upset and are afraid to lose students' respect if they are not able to explain specific terms or do not understand some notions in the specialism they teach. The lack of knowledge has a side effect on teachers' confidence (especially among young teachers). An ESP teacher has to understand and inform the students that his/her job is to teach them English, not to be a subject specialist and not to be frustrated by the knowledge gap. On the other hand, it is important to mention that there is a need for universities to develop and implement a CPD (Continuing Professional Development) policy for teachers of English with a requirement for regular updates in teaching methodology and professional trips to other countries (Bolitho \& West, 2017, p.84).

Surprisingly, $100 \%$ of the university teachers, who took part in this study, find introspection a useful way of researching learners' needs (not only experienced teachers, but the young ones (aged 23-24), gave such responses as well). Scholars consider introspection not very useful, as there are serious dangers connected with over-reliance on it. All assumptions (which can appear to be false) must be checked from other sources (British Council, 2013).

Consulting with an expert in a definite field is thought to be really helpful by both the teachers (altogether 88\% marked this as useful) and scientists. The workplace tours are considered to be very useful by $100 \%$ of respondents as well.

The Internet is also a very effective means of getting different information as well as the way of researching learners' needs. However, ESP teachers need to be selective and careful. There is no doubt that teachers who make effective use of the Internet as a research tool have a huge advantage over teachers in the pre-internet age.

Using textbooks can be quite useful, which can be proved by $100 \%$ of teachers who marked this point. Textbooks are good for introducing important field concepts. Though there are not many good ESP course 
books relating to different specialisms. Especially university teachers should be careful not to overuse course books published in Ukraine, which apply Grammar-based approach with such activities as read, translate and retell the text; do grammar exercises (while the Grammar is not the core of ESP at all).

Training courses and professional qualifications for the given field are very useful. $100 \%$ of ESP teachers (despite their position at university or teaching experience), who took part in our research, understand this. If teachers do not have the necessary skills themselves, then it is an unrealistic expectation for them to help students (Poedjiastutie \& Oliver, 2017).

Starting in 2014 up to 2017 in partnership with the Ministry of Education and Science of Ukraine, the British Council conducted in-depth studies of 15 universities across the country to evaluate the current English provision as well as the role and status of the English language. Various questionnaires, observation and the Aptis test were used. One of the focuses was teachers of English for Specific Purposes (ESP). The results of the British Council's Aptis test, which provides results aligned to the CEFR (Common European Framework of Reference for Languages), demonstrated that, while a majority (61 per cent) of tested university teachers reached level $\mathrm{C}$, a significant proportion (39 per cent) did not and a few (4 per cent) were assessed at only B1 or even A2 levels. This weakness is likely to affect the quality of the English teaching in universities of Ukraine (Bolitho \& West, 2017).

Training courses for teachers can be a goldmine of useful information and aids. However, in many cases, they can be rather expensive and time-consuming. In 2014 The British Council introduced "The English for Universities" project in our country. Since then 15 Ukrainian universities have participated in various trainings and workshops for ESP, EMI (English as the Medium of Instruction: Teaching which is delivered through the medium of the English language) teachers and heads of language departments. It is necessary to mention that this project is funded and is free of charge for university teachers.

The results of our research have also shown that only $12 \%$ of the interviewed teachers find support groups very useful. $76 \%$ think that they are quite useful and $12 \%$ find them a waste of time. It differs from the opinions of the educators and scholars who consider support groups to be very useful (British Council, 2013). There are many teachers around the world teaching similar courses; therefore it makes sense for them to share their ideas, experiences and concerns. Good examples include IATET (the International Association of Technical English Trainers), EULETA (the European Legal English Teachers' Association) and various special interest groups (SIGs) of IATEFL (the International Association of Teachers of English as a Foreign Language), such as ESP SIG (English for Specific Purposes).

Unfortunately, almost half of respondents (48\%) identified watching professionals in action a as waste of time, though this option is very useful. This is probably the best way to understand what learners actually will do in future. Go to the workplace and watch specialists in action. The only disadvantage exists that this can be difficult to arrange.

$85 \%$ of respondents find TV programs and online films useful $(70 \%$ - very useful and $15 \%$ - quite useful). This way can be such indeed, but ESP teachers should be really selective. They have to check thoroughly if these sources are relevant to learners' future profession.

Surprisingly, $90 \%$ of university teachers, who took part in this study, think that using magazines is a useful way of researching learners' needs. Again, it depends on what source to use. Specialised journals can really be helpful.

The absence of responses for the last point (other ways) proves our assumption that ESP university teachers either are not much familiar with the topic of needs analysis or only use the ways that are the simplest to arrange (such as orally interviewing students) and the sources at hand (the Internet, course books etc.).

Different ways (or methods) can be used to analyse learners' needs (diaries and journals; role plays and simulations; classroom observation; various needs analysis forms, which can be found online or created by teachers; even experiments and case studies). Some of them are more time consuming, others will require more expertise and will be more appropriate for particular situations. Scholars and educators recommend different ways and emphasise that multiple sources will increase the quality of gathered information (Long, 2005, p.32-33).

This research was conducted among sixty university teachers. For better understanding and comprehensive covering of the problem the wider scope of participants should be used, considering their age, academic background and locality.

\section{Conclusions}

To sum up, the various definitions of ESP with the emphasis on learners' needs were introduced in this article. It is evident that the ultimate goal of ESP classes is to provide lessons which satisfy students' language needs in various professional situations. The case study, presented in this work, was designed to 
explore whether ESP teachers from Ukrainian universities are aware of the importance of needs analysis, its forms and the most common ways used in their work. In conclusion, it is important to mention that though the ESP teachers from Ukrainian higher educational institutions, who took part in this research, understand the importance of their learners' needs, the results of the research showed that they are unaware of the ways how this information can be collected. All surveyed teachers get information about their students' needs simply by interviewing them. There is a huge reliance on their own experience (which does not even depend on the age or a position of the teacher), though this can lead to false assumptions.

The results of the survey conducted in higher educational institutions among ESP teachers have also shown that the majority of them consult with subject teachers and students about topics, terminology, materials for teaching their specialism. This research has lead to the conclusion that the usage of different ways and multiple sources will increase the quality of gathered information about ESP learners' needs.

The importance of support groups, training courses and CPD were also emphasised in this paper as the ways of overcoming possible problems in teaching ESP and filling in teachers' knowledge gap. The following recommendations will help university teachers not only in learning various ways of identifying learners' needs, but evolving in the professional sphere of teaching ESP as well.

- Ask a content specialist (subject lecturer at your institution, peer, former student) to become your mentor or provide guidance/advice on an occasional basis.

- Attend subject content classes at your institution.

- Work through some of the key texts on your learner's recommended reading list.

- Become a member of a community in the subject area (online forums, special interest groups of a national/international teaching association).

- Set up your own community for ESP teachers in your specific field.

- Subscribe to a specialised (online) journal.

- Watch presentations in the specialist area on TED Talks or similar.

- Attend conferences in the specialist area.

- Participate in workshops organised by special interest groups.

Future work in this field of research should focus on problematic issues, specifics and provision of conditions and resources for teaching ESP at Ukrainian universities. Our research provides the framework for further studies to assess the level of intrinsic and extrinsic motivation in English language learning based on university students' needs.

\section{References:}

Bolitho, R., West, R. (2017). The internationalisation of Ukrainian universities: the English language dimension. Kyiv, Ukraine: Stal.

Bojovic, M. (2006).Teaching Foreign Language for Specific Purposes: Teacher Development. In Mateja Brejc (Ed.), Proceedings of the 31st Annual ATEE Conference (pp.487-493). Portorož, Slovenia: Convention Center Bernardin. Retrieved 10 November 2017 from http://www.pef.uni-lj.si/atee/

Certificate in Vocational English Language Teaching (CiVELT). (2013). Module 8 - Understanding your learners' field. London: British Council.

Certificate in Vocational English Language Teaching (CiVELT). (2013). Module 9 - Understanding needs. London: British Council.

Chovancova, B. (2014). Needs analysis and ESP course design: self-perception of language needs. Studies in Logic, Grammar and Rhetoric, 38(51), 43-57. https://doi.org/10.2478/slgr-2014-0031

Dudley-Evans, T., St.John, M. (1998). Developments in English for Specific Purposes: A multi-disciplinary approach. Cambridge: Cambridge University Press.

Finney, D. (2002). The ELT curriculum: A flexible model for a changing world. In: Richards, J. C. \& Renandya, W. A. (Eds.), Methodology in language teaching: An anthology of current practice (pp. 69-79). Cambridge: Cambridge University Press.

Flowerdew, L. (2013). Needs Analysis and Curriculum Development in ESP. In B.Paltridge, S. Starfield (Eds.), The Handbook of English for Specific Purposes (pp. 325-346). Oxford: John Wiley \& Sons, Inc.

Hutchinson, T. \& Waters, A. (1987). English for Specific Purposes: A learner-centered approach. Cambridge: Cambridge University Press.

Hyland, K. (2006). English for Academic Purposes. London: Routledge.

Lavrysh,Y. (2016). Peer and self-assessment at ESP classes: case study. Advanced Education, 6, 60-68. https://doi.org/10.20535/2410-8286.85351

Long, M. H. (2005). Second Language Needs Analysis. Cambridge: Cambridge University Press.

Poedjiastutie1, D.,\& Olive, R. (2017). Exploring Students' Learning Needs: Expectation and Challenges. English Language Teaching; 10 (10), 124-133. https://doi.org/10.5539/elt.v10n10p124

Songhori, M. H. (2008). Introduction to Needs Analysis. English for Specific Purposes world, 4. Retrieved 2 December, 2017 from http://www.finchpark.com/courses/tkt/Unit_14/Introduction.pdf

Soroka, I. (2017). Peculiarities of teaching ESP at Ukrainian Universities. European Humanities studies: State and Society, 2, $174-$ 184. Retrieved 10 November, 2017 from http://www.ehs-ss.pl

West, R. (1994). Needs analysis in language teaching. Language Teaching, 27(1), 1-19. https://doi.org/10.1017/S0261444800007527 